\title{
Boron Deficiency in Palms ${ }^{1}$
}

Timothy K. Broschat ${ }^{2}$

\section{Symptoms}

Boron (B) deficiency causes a wide array of symptoms, not only among species of palms, but also within a single species. Symptoms always occur on newly emerging leaves, and remain visible on these leaves as they mature and are replaced by younger leaves.

One of the earliest symptoms of B deficiency on Dypsis lutescens (areca palm) and Syagrus romanzoffiana (queen palm) is transverse translucent streaking on the leaflets. In many species including Cocos nucifera (coconut palm), Elaeis guineensis (African oil palm), and S. romanzoffiana, mild B deficiency is manifested as sharply bent leaflet tips, commonly called "hookleaf" (Figure 1). These sharp leaflet hooks are quire rigid and cannot be straightened out without tearing the leaflets. In some species, these "hooks" drop off.

Another symptom associated with chronic B deficiency in S. romanzoffiana is the production of weak, narrow leaflets towards the tips of newly emerging leaves. These leaflets often drop off, leaving the rachis tip devoid of leaflets (Figures 2 and 3)

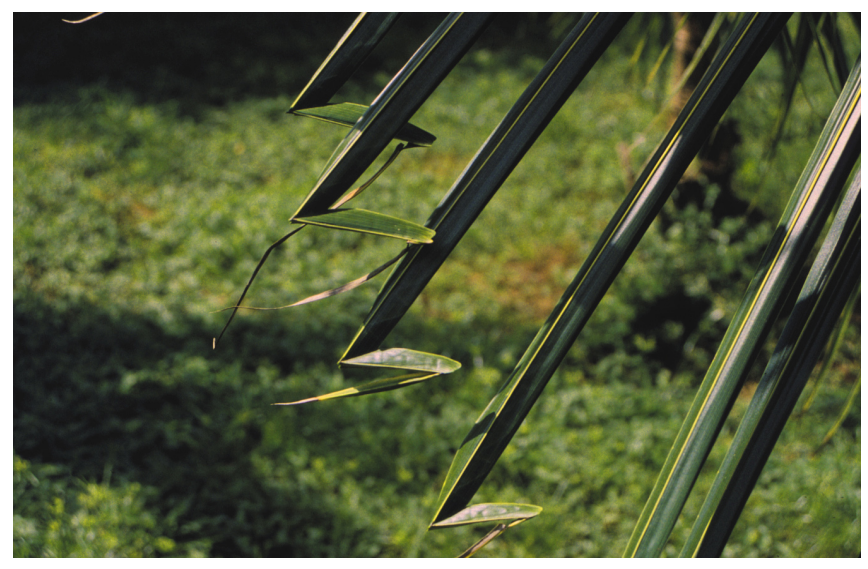

Figure 1. Cocos nucifera with "hookleaf", a mild syptom of B deficiency. Credits: T.K. Broschat

Boron deficiency can be very transient in nature, often affecting a developing leaf primordium for a very short period of time (e.g., 1 to 2 days). This temporary shortage of B can cause necrosis (death) of the primordial spear leaf for a distance of about 1 to $2 \mathrm{~cm}$. When such leaves eventually expand, this "point" necrosis affects the tips of all leaflets intersected by that necrotic point, the net result being the appearance of a blunt, triangular truncation of the leaf tip (Figures 4 and 5). This pattern can be repeated as many as 3 times during the development of a single leaf of Cocos nucifera (about 5 weeks) (Figure 6).

1. This document is ENH1012, one of a series of the Environmental Horticulture Department, Florida Cooperative Extension Service, Institute of Food and Agricultural Sciences, University of Florida. Original publication date September 2005. Visit the EDIS Web Site at http://edis.ifas.ufl.edu.

2. Timothy K. Broschat is Professor, Environmental Horticulture Department, Fort Lauderdale Research and Education Center, Institute of Food and Agricultural Sciences, University of Florida, Fort Lauderdale, FL 33314

The Institute of Food and Agricultural Sciences (IFAS) is an Equal Opportunity Institution authorized to provide research, educational information and other services only to individuals and institutions that function with non-discrimination with respect to race, creed, color, religion, age, disability, sex, sexual orientation, marital status, national origin, political opinions or affiliations. U.S. Department of Agriculture, Cooperative Extension Service, University of Florida, IFAS, Florida A. \& M. University Cooperative Extension Program, and Boards of County Commissioners Cooperating. Larry Arrington, Dean 


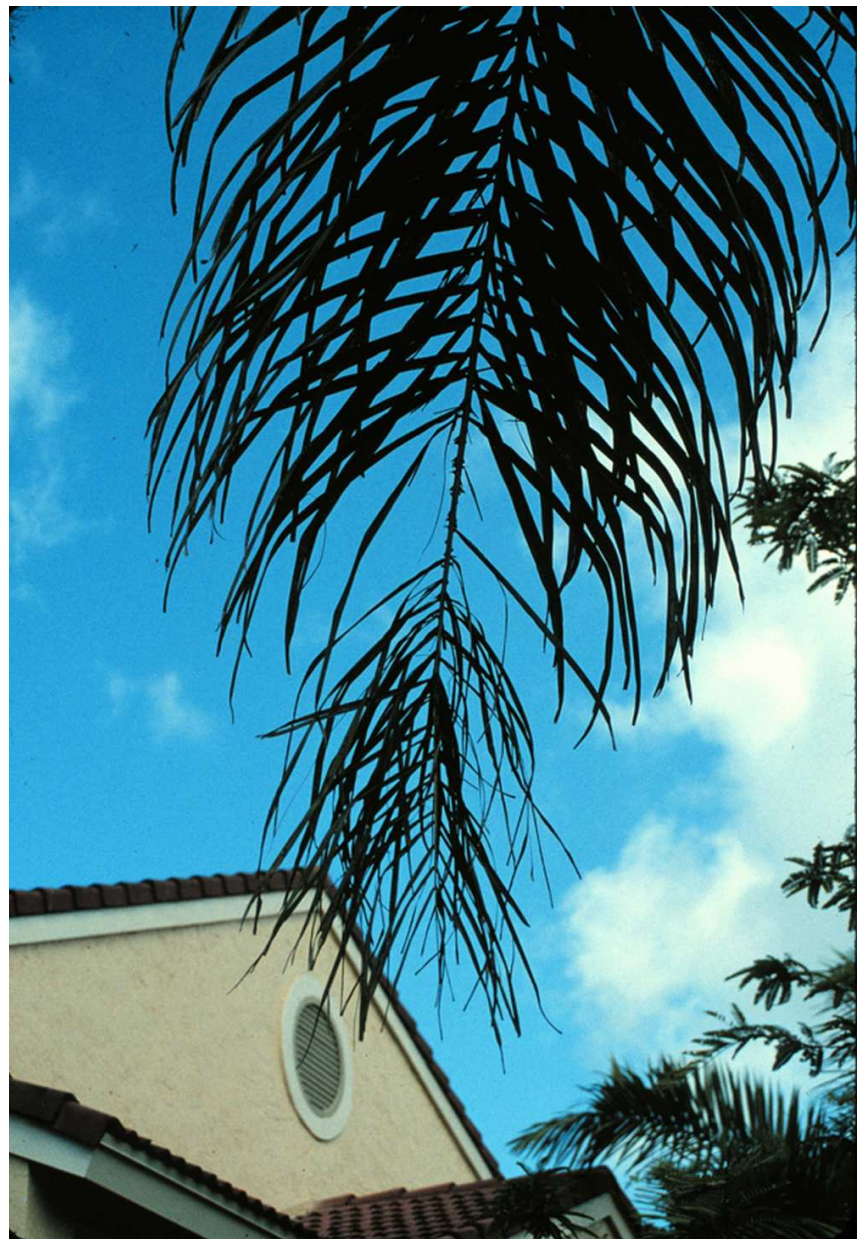

Figure 2. Small thin leaflets at the tip of a B-deficient Syagrus romanzoffiana. Credits: T.K. Broschat

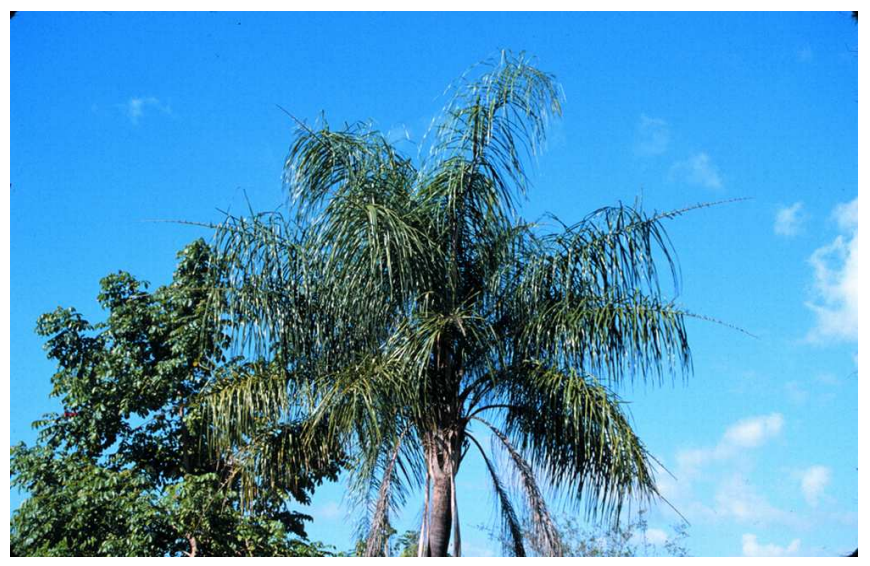

Figure 3. Bare leaf tips on B-deficient Syagrus romanzoffiana. Credits: T.K. Broschat

One of the most common symptoms of B deficiency is the failure of newly emerging spear leaves to open normally. They may be tightly fused throughout their entire length, or the fusion can be restricted to basal or distal parts of the spear leaf. In

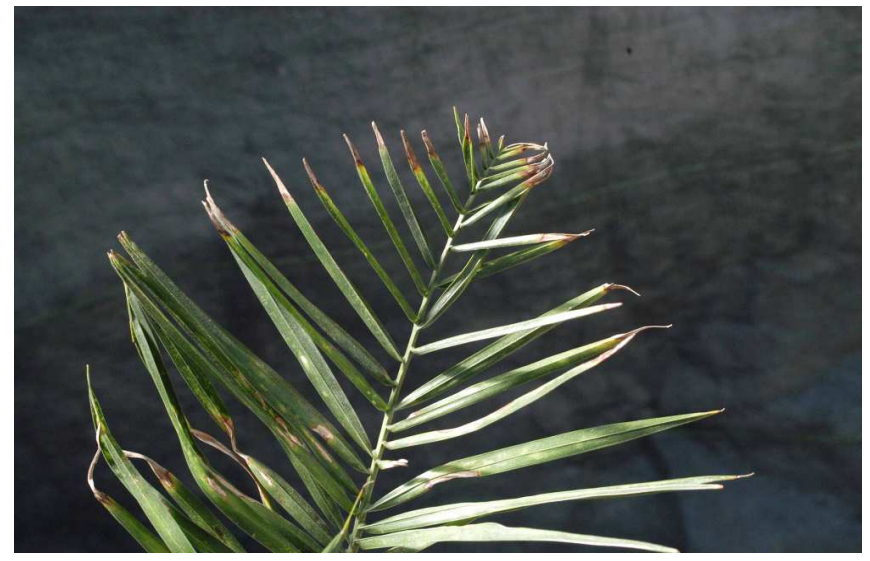

Figure 4. Leaf tip of B-deficient Phoenix roebelenii (pygmy date palm) showing necrotic truncation in an inverted "V" shape. Credits: T.K. Broschat

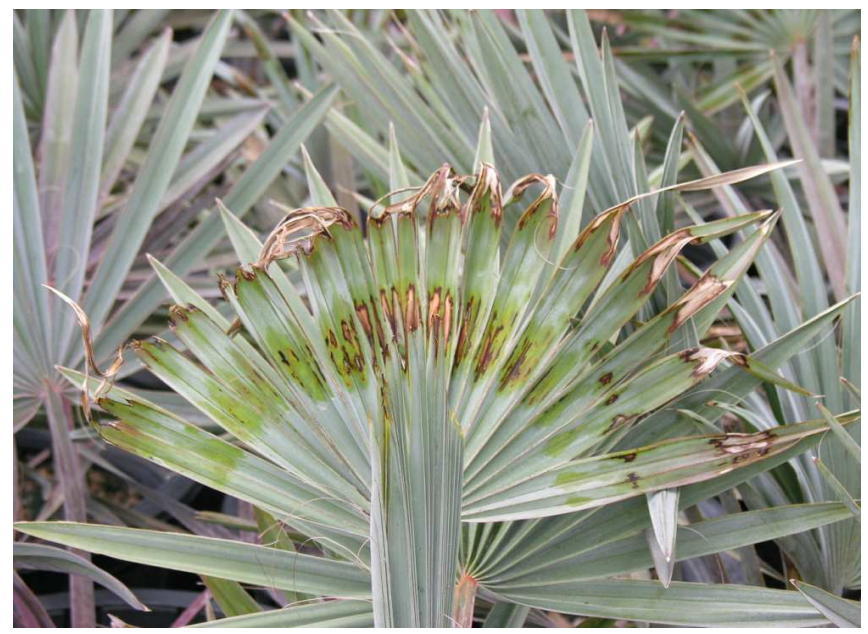

Figure 5. Boron deficiency of Bismarckia nobilis (Bismarck palm) showing necrosis at two separate times during the development of this leaf. Credits: T.K. Broschat

a chronic state, multiple unopened spear leaves may be visible at the apex of the canopy (Figures 7 and 8).

Perhaps the most unusual symptoms of chronic B deficiency is the tendency for the entire crown to bend in one direction (Figures 9 and 10). This is one form of epinasty that can also cause twisting of petioles and leaves or sharp bends in the petiole, resulting in a single new leaf growing downward along the trunk (Figure 11). These epinastic symptoms are believed to be caused by a B deficiency-induced decrease in IAA oxidase activity and therefore excessive auxin concentrations within the leaves.

Boron deficiency in its acute form produces yet other symptoms. Often leaves emerge greatly reduced in size and crumpled in a corrugated fashion 


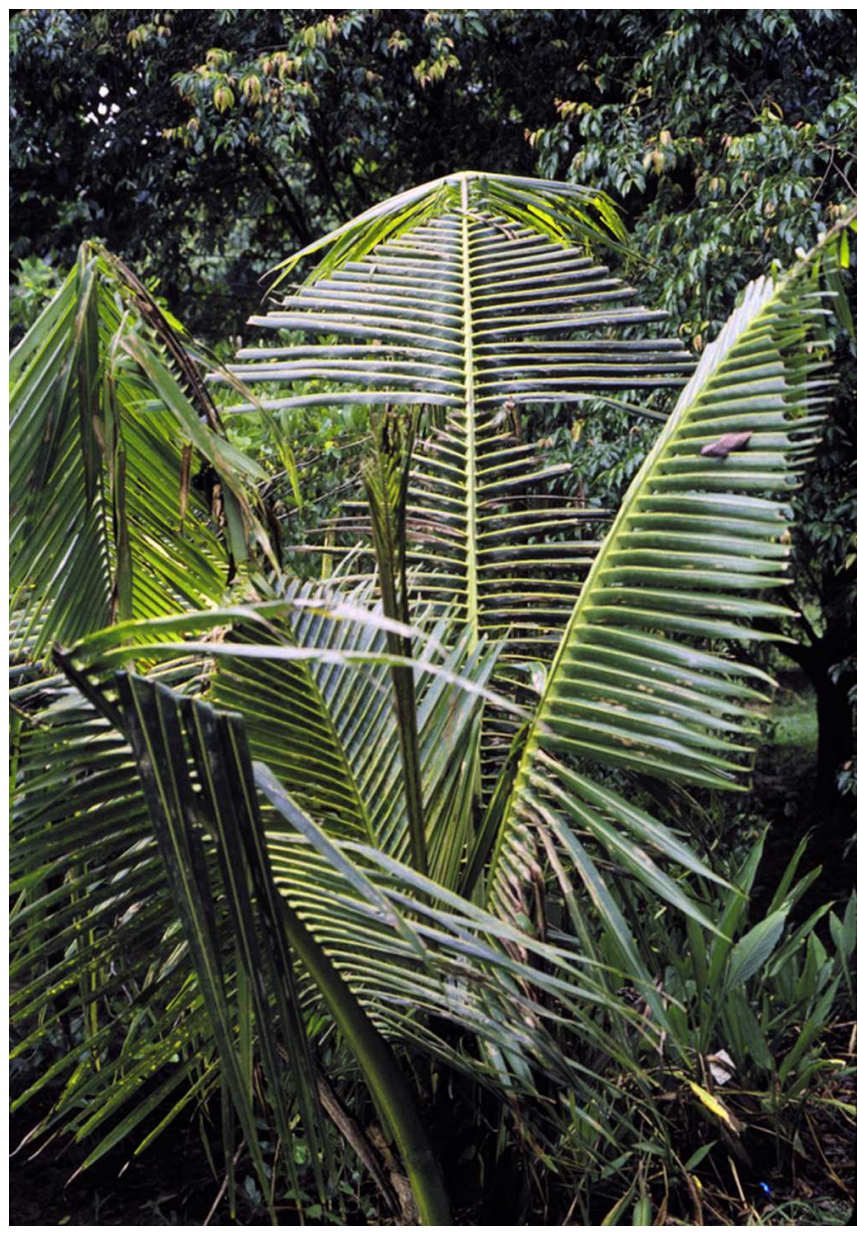

Figure 6. Boron-deficient Cocos nucifera showing a series of inverted "V" shaped truncations on each leaf. These leaf constrictions represent separate temporary $B$ deficiencies caused by a series of heavy rainfalls. Credits: T.K. Broschat

(accordion-leaf) (Figures 12 and 13). Palms may grow out of these symptoms or the deficiency can kill the meristem.

Boron-deficient palms often abort their fruits prematurely and inflorescences may have extensive necrosis near their tips (Figures 14 and 15). These symptoms are very similar to those of lethal yellowing in species affected by that disease. The calyx end of fallen coconuts from LY-infected Cocos nucifera will be blackened, whereas coconuts from B-deficient trees will not have this blackened end.

\section{Cause}

Boron deficiency is caused by insufficient B in the soil. Boron is readily leached through most soils, with a single heavy rain event temporarily leaching most available B out of the root zone. When this leaching stops, B released from decomposing organic

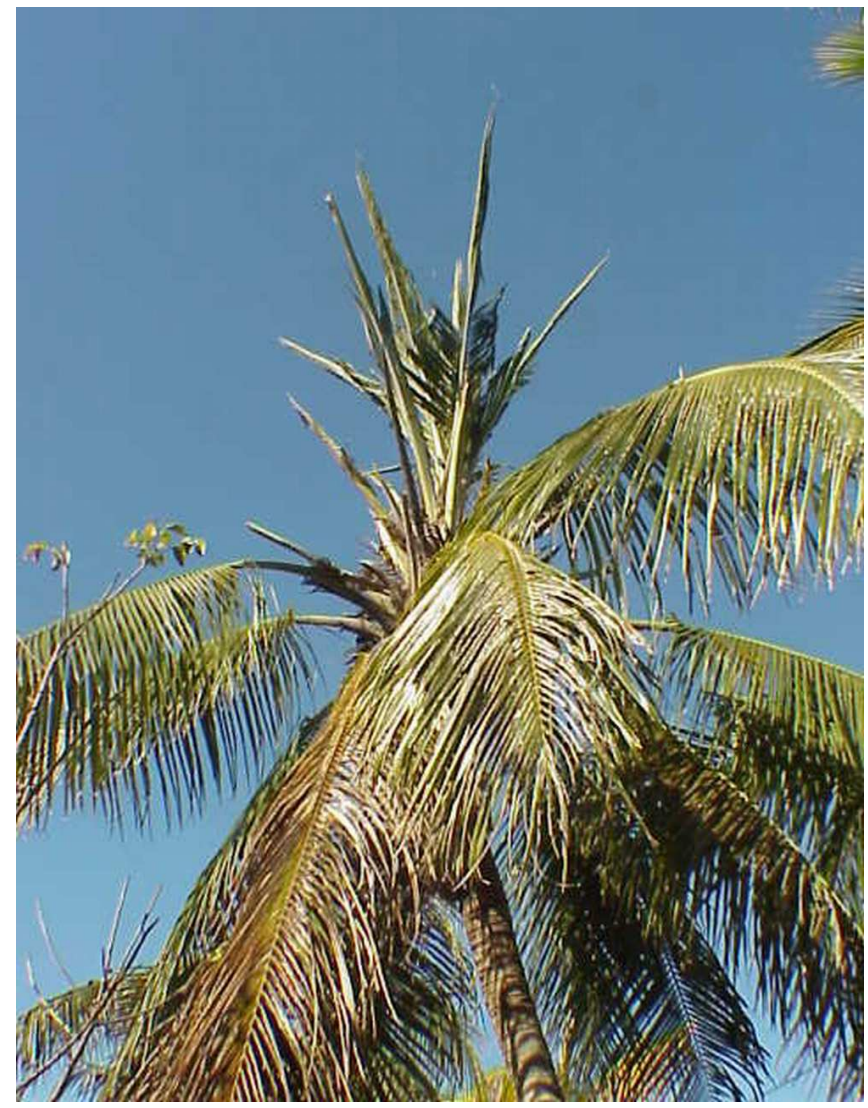

Figure 7. Multiple unopened spear leaves on a chronically B-deficient Cocos nucifera. Credits: T.K. Broschat

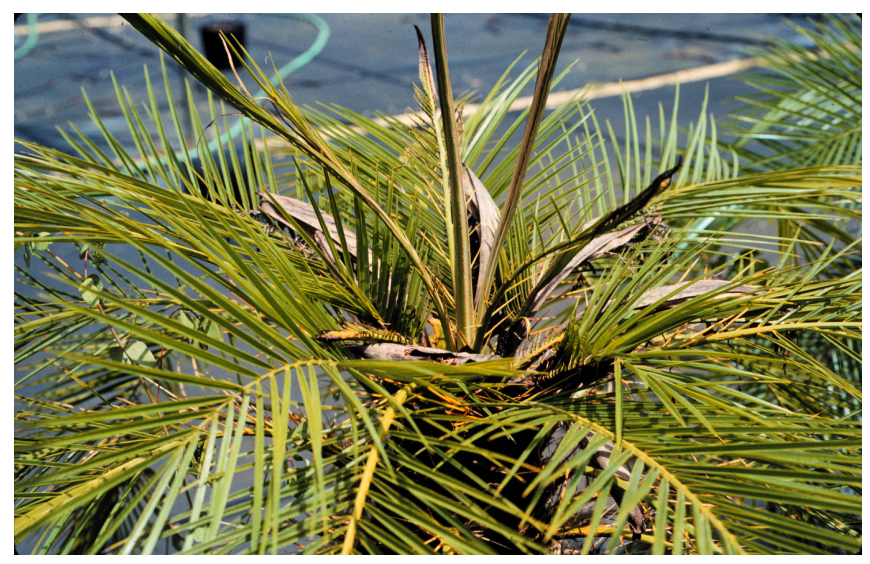

Figure 8. Mulitple unopened spear leaves on B-deficient Phoenix roebelenii. Credits: T.K. Broschat

matter will again provide adequate B for normal palm growth in most cases.

\section{Occurrrence}

Boron deficiency is very widespread on palms growing in wet climates throughout the world, but can also occur in desert situations. It was considered rather uncommon in Florida, but for reasons not yet understood, has become a widespread and serious 


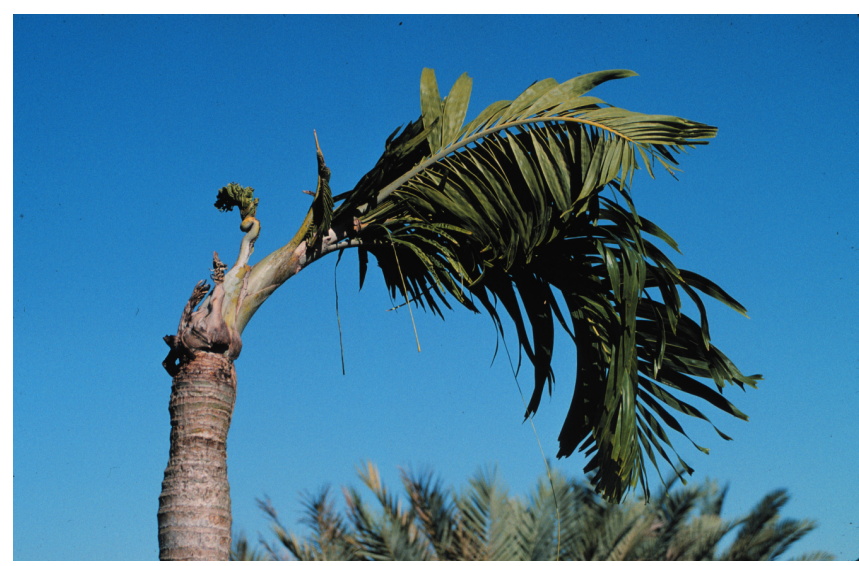

Figure 9. Chronic B deficiency on Adonidia merrillii (Christmas palm) showing trunk bending. The tiny crumpled leaves indicate that the deficiency was at one time acute, but was subsequently alleviated to some degree. Credits: T.K. Broschat

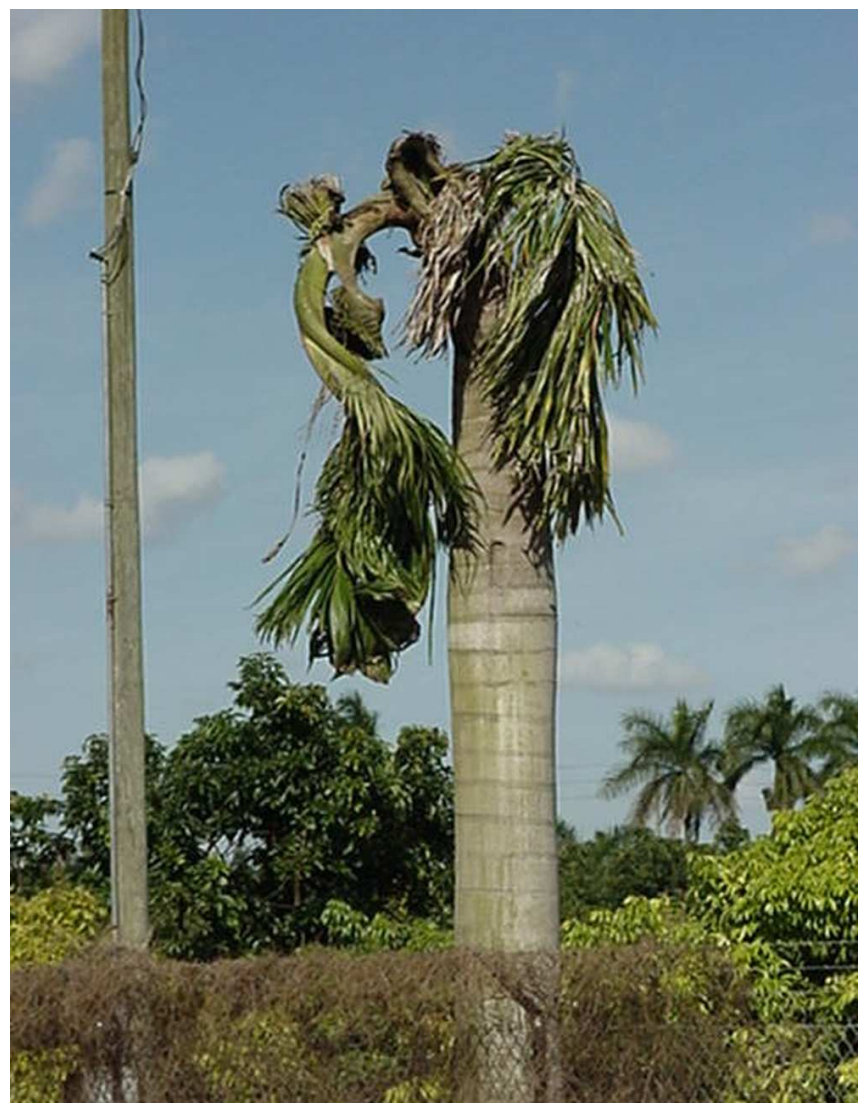

Figure 10. Severe epinasty in Roystonea regia (Cuban royal palm) due to $B$ deficiency. Note also the small size of some of the leaves. Credits: T.K. Broschat

problem on landscape palms throughout the state in recent years. Abnormally high rainfall associated with the 4 hurricanes that hit Florida in 2004 are thought to be one factor. Use of fertilizers that contain no B is an obvious cause, but B deficiency can occur in properly fertilized palms as well. This is

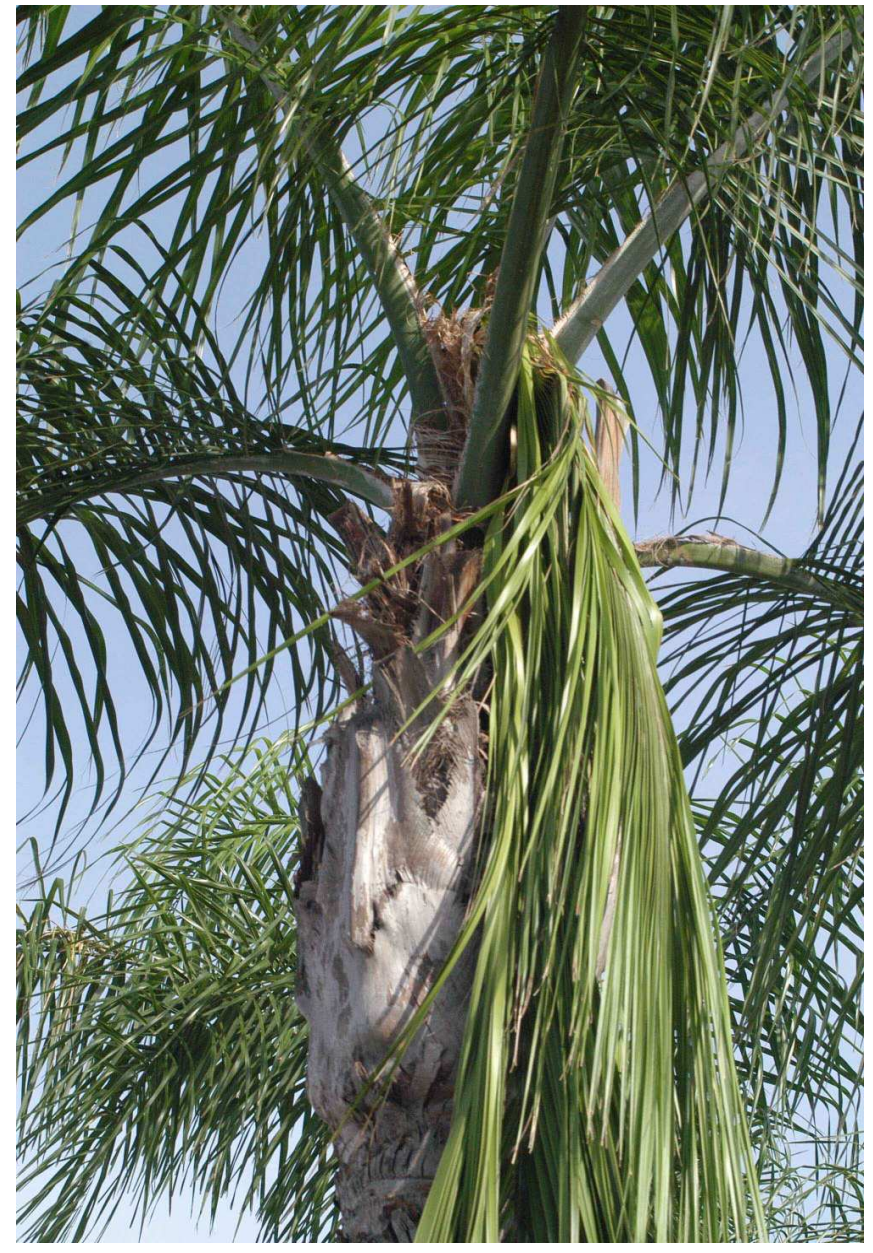

Figure 11. Bent new leaf of Syagrus romanzoffiana caused by B deficiency. Credits: T.K. Broschat

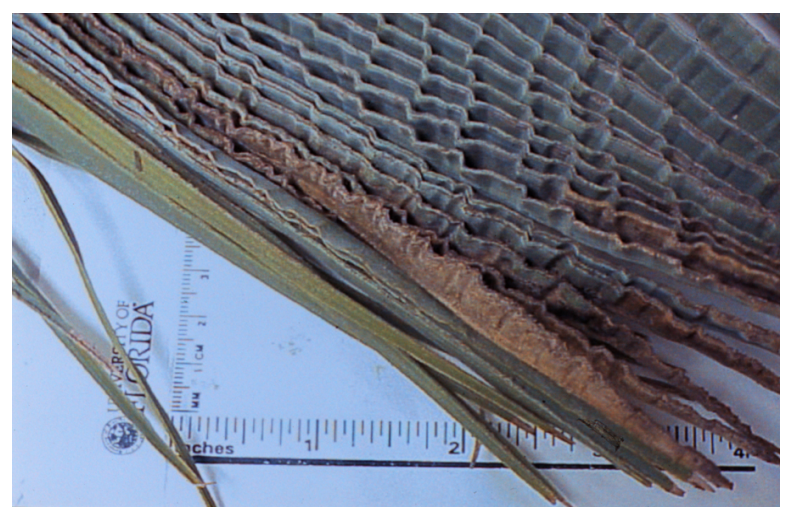

Figure 12. Accordion-leaf in Syagrus romanzoffiana, a symptom of B deficiency. Credits: T.K. Broschat

most likely due to the exclusive use of water-soluble B sources in blended palm fertilizers that are highly susceptible to leaching. Boron deficiency has been observed in container-grown palms, but it is rather rare in this environment. 


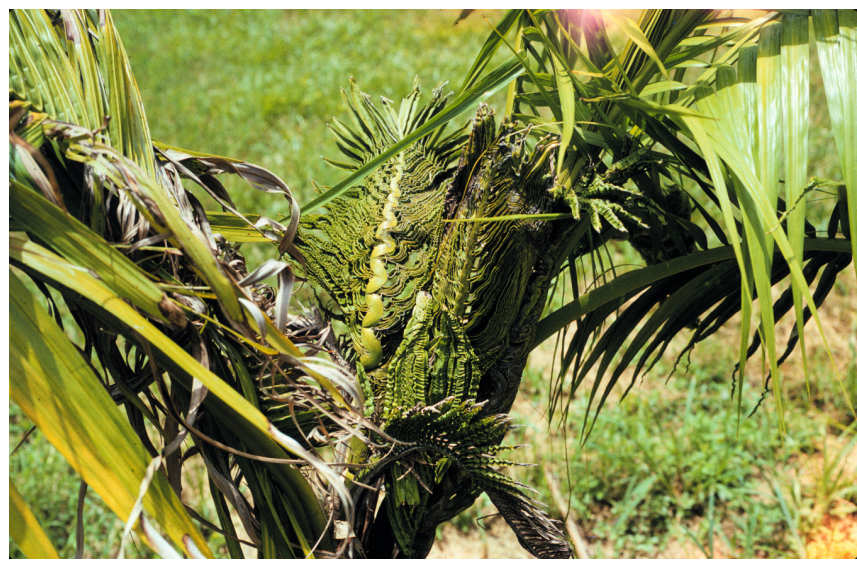

Figure 13. Acute B deficiency in Heterospathe elata (sagisi palm) showing small crumpled new leaves. Credits: T.K. Broschat

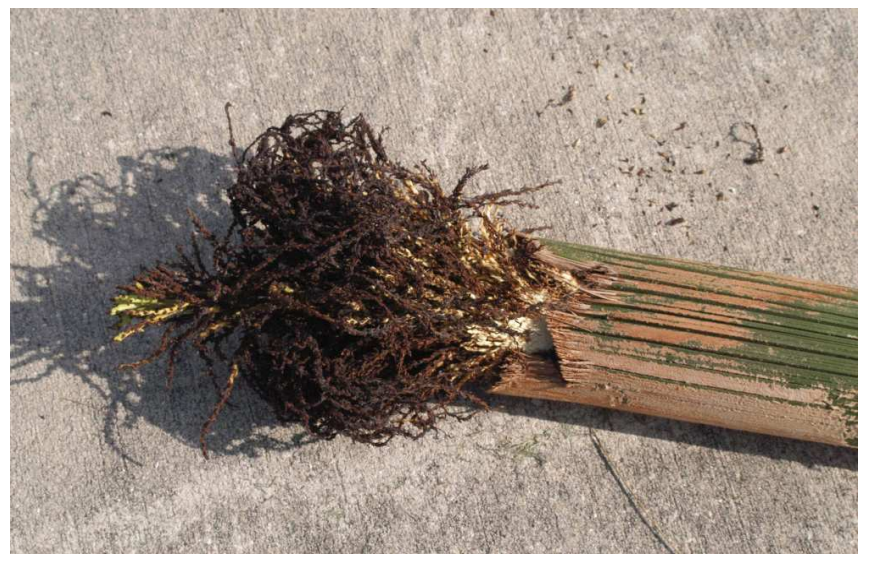

Figure 14. Necrotic inflorescence (flower stalk)of Syagrus romanzoffiana caused by B deficiency. Credits: T.K. Broschat

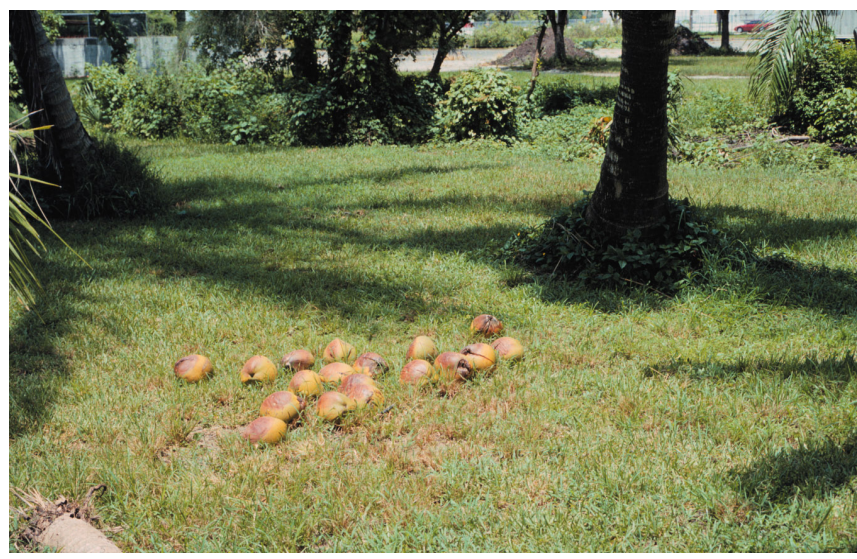

Figure 15. Premature fruit drop in Cocos nucifera caused by $\mathrm{B}$ deficiency. Credits: T.K. Broschat

\section{Diagnostic Techniques}

Boron deficiency symptoms are quite distinctive and are usually sufficient for diagnosis by themselves. Manganese deficiency in Cocos nucifera produces symptoms similar to those of B deficiency, but no other common deficiency produces symptoms that could be confused with those of B deficiency.

Because B deficiency is so transient in nature, the element is immobile within the palm (cannot move from one leaf to another), and deficiencies affect only leaf primordia developing within the bud area, leaf analysis is not particularly useful. Leaf analysis tells you the B status of the single leaf that you sampled, but that is not the current B status of the newly developing leaves within the bud area. Rather, it is the B status of the palm 4 or 5 months ago when the sampled leaf itself was in the developmental stage within the bud. The B status of the palm is likely to have changed considerably one way or another during 4 or 5 months since the affected leaf became old enough to sample. Thus, leaf analysis, or even leaf symptoms, unless the deficiency is chronic (regularly occurring), cannot tell you about the current B status of a palm. Similarly, soil analysis is not recommended for diagnosis of B deficiency.

\section{Management}

Fertilization to correct or prevent B deficiency in palms is problematic at this time. The only B sources currently used on palms are water soluble sodium borates. In high rainfall climates such as that of Florida, an application of water-soluble B can be completely leached out of the root zone with a single heavy rain shower. Slow release B fertilizers are an obvious solution to this problem, but rates have yet to be determined for palms. Several slow release B fertilizers being tested at the University of Florida for their release characteristics appear to release slowly over a period of at least one year. Thus regular use of these products could result in a build-up of B within the soil to potentially toxic levels (Figure 16).

Unfortunately, the difference between deficiency and toxicity levels of B within palms is rather small and correction of a B toxicity caused by over-application of slow-release B fertilizers could be very difficult. 


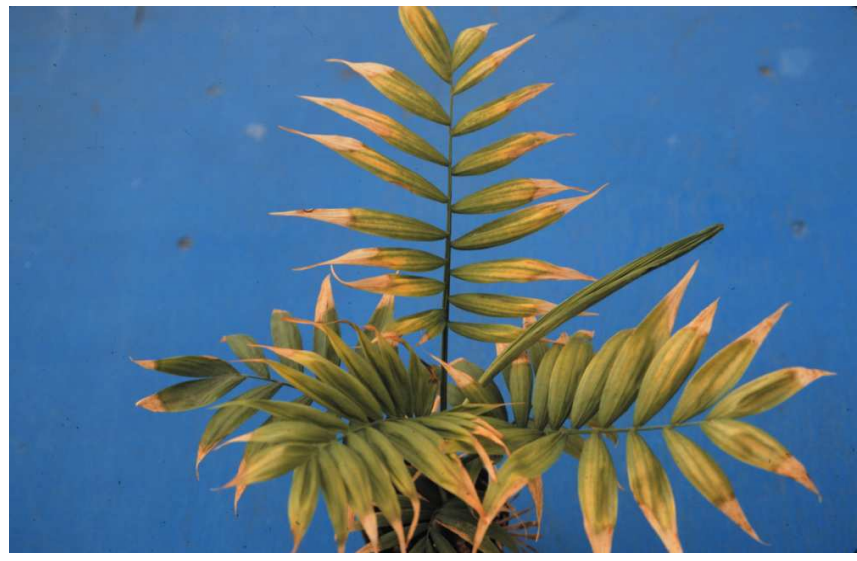

Figure 16. Boron toxicity on Chamaedorea elegans (parlor palm). Credits: T.K. Broschat

Current recommendations for correcting B deficiencies in palms are intentionally conservative because of the potential for toxicity. Dissolve about $4 \mathrm{oz}$ of Solubor or Borax in 5 gallons of water and drench this into the soil under the palm canopy. Do not repeat this for at least 5 months, since it will take this long to see the results of the first application.

\section{Selected References}

Broschat, T.K. 1984. Nutrient deficiency symptoms in five species of palms grown as foliage plants. Principes 28:6-14.

Brunin, C. and P. Coomans. 1973. La carence en bore sur jeunes cocotiers en Côte DIvoire.

Oléagineux 28:229-234.

Bull, R.A. 1961. Studies on the deficiency symptoms of the oil palm. 3. Micronutrient deficiency symptoms in oil palm seedlings grown in sand culture. J. West African Inst. Oil Palm Res. $3: 265-272$.

Manciot, E., M. Ollagnier, and R. Ochs. 1979-80. Mineral nutrition of the coconut around the world. Oléagineux 34:511-515; 576-580; 35:23-27.

Marlatt, R. B. 1978. Boron deficiency and toxicity symptoms in Ficus elastica and Chrysalidocarpus lutescens. HortScience 13:442-443.

Ollagnier, M. and G. Valverde. 1968. Contribution à letude de la carence en bore du palmier à huile.

Oléagineux 23:359-366. 